\title{
Potential energy surfaces for small alcohol dimers. II. Propanol, isopropanol, t-butanol, and sec-butanol
}

\author{
Richard L. Rowley \\ rowley@byu.edu \\ Christopher M. Tracy \\ Tapani A. Pakkanen
}

Follow this and additional works at: https://scholarsarchive.byu.edu/facpub

Part of the Chemical Engineering Commons

\section{Original Publication Citation}

Rowley, Richard L., Christopher M. Tracy, and Tapani A. Pakkanen. "Potential energy surfaces for small alcohol dimers. II. Propanol, isopropanol, t-butanol, and sec-butanol." The Journal of Chemical Physics 127 (27)

\section{BYU ScholarsArchive Citation}

Rowley, Richard L.; Tracy, Christopher M.; and Pakkanen, Tapani A., "Potential energy surfaces for small alcohol dimers. II. Propanol, isopropanol, t-butanol, and sec-butanol" (2007). Faculty Publications. 243. https://scholarsarchive.byu.edu/facpub/243 accepted for inclusion in Faculty Publications by an authorized administrator of BYU ScholarsArchive. For more information, please contact ellen_amatangelo@byu.edu. 


\title{
Potential energy surfaces for small alcohol dimers. II. Propanol, isopropanol, $t$-butanol, and sec-butanol
}

\author{
Richard L. Rowley and Christopher M. Tracy \\ Department of Chemical Engineering, Brigham Young University, Provo, Utah 84602 \\ Tapani A. Pakkanen \\ Department of Chemistry, University of Joensuu, FIN-80101 Joensuu, Finland
}

(Received 21 February 2007; accepted 14 May 2007; published online 12 July 2007)

\begin{abstract}
Potential energy landscapes for homogeneous dimers of propanol, isopropanol, tert-butanol, and sec-butanol were obtained using 735 counterpoise-corrected energies at the MP2/6-311 $+\mathrm{G}(2 d f, 2 p d)$ level. The landscapes were sampled at 15 dimer separation distances for different relative monomer geometries, or routes, given in terms of the yaw, pitch, and roll of one monomer relative to the other and the spherical angles between the two monomer centers (taken as the $\mathrm{C}$ atom attached to the $\mathrm{O}$ ). The resultant individual energy surfaces and their complex topographies were also regressed using a site-site pair potential model using a modified Morse potential that provides a mathematically simple representation of the landscapes suitable for use in molecular simulations. Generalized Morse parameters were also obtained for this model from a composite regression of these energy landscapes and those previously reported for methanol and ethanol. The quality of fit for all these energy landscapes suggests that these site parameters have transferability for possible use on other alcohols. (C) 2007 American Institute of Physics. [DOI: 10.1063/1.2747244]
\end{abstract}

\section{INTRODUCTION}

In a companion paper, ${ }^{1}$ we reported counterpoisecorrected dimer potential energy landscapes for rigid monomers of methanol and ethanol. These dimer energy surfaces were obtained from $a b$ initio supermolecule calculations using MP2/6-311+G(2df,2pd). Similar calculations are used in this study to obtain the energy landscapes for dimers of alcohols containing three or four carbon atoms. Such potential energy surfaces are important in relating condensedmatter thermophysical properties to molecular interactions and for quantitative property predictions using those interactions in methods such as molecular dynamics and Monte Carlo simulations. We refer readers to the discussion and references cited in Ref. 1 for background on appropriate methods for obtaining dimer energy landscapes and their validation in simulation work.

Analytical representation of the potential energy surface is generally required for its use in simulations. In the companion paper, we showed that the multidimension, complex potential energy surfaces obtained for methanol and ethanol could be adequately modeled as the pairwise summation of site-site interactions,

$$
U=\sum_{i=1}^{\mathrm{NS}} \sum_{j=1}^{\mathrm{NS}} u_{i j}\left(r_{i j}\right),
$$

where $U$ is the potential energy, NS is the number of sites on each monomer, and $u_{i j}$ is a spherically symmetric site-site pair potential energy that is a function only of the separation distance between the sites $r_{i j}$. We have used an all-atom model in which NS is equal to the number of atoms in the monomer. A modified Morse model,

$$
u_{i j}=-\varepsilon_{i j}\left(1-\left\{1-\exp \left[-A_{i j}\left(r_{i j}-r_{i j}^{*}\right)\right]\right\}^{2}\right)+\frac{z_{i} z_{j} e^{2}}{4 \pi \varepsilon_{0} r_{i j}},
$$

was used to represent the interatomic interactions. In this model, $\varepsilon, A$, and $r^{*}$ are adjustable parameters representing the attractive well depth, well shape factor, and the location of the minimum in the potential well, respectively. Equation (2) uses fractional point charges $z_{i}$ ( $e$ is electron charge and $\varepsilon_{0}$ is the free space permittivity) assigned to nuclear sites $i$ to model Coulombic interactions within the molecule. The use of such point charges is a common means of separately modeling interactions due to permanent charge distributions and dispersion interactions. However, it should be remembered that point charge interactions are a rudimentary representation of the actual interactions between spatially complex electrostatic molecular surfaces. For example, a Mulliken population analysis assigns point charges based on a partitioning of the electron density between the atoms, while an electrostatic-potential (ESP) method, such as that used to obtain the point charges in this study, regresses a set of point charges that best reproduces the electrostatic potential at a grid of points surrounding the molecule. With this in mind, in Ref. 1 we regressed the ab initio methanol and ethanol energy landscapes to obtain parameters in Eq. (2) in two different ways, both of which adequately represented the complexity of the dimer energy surfaces. Using ESP charges and Eq. (2) as written, we obtained Morse potential parameters representing only the repulsion and dispersion interactions. In the second method, we obtained the parameters $\varepsilon$, $A$, and $r^{*}$ by regressing the ab initio landscapes without the point charges. In this case, the Morse potential models the total interactions between the monomers. Interestingly, this 


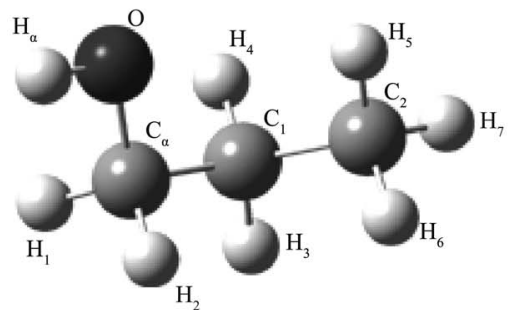

\begin{tabular}{|c|c|c|c|c|c|}
\hline Bond & Bond Length $(\AA)$ & Angle & Angle (deg) & Dihedral & Dihedral (deg) \\
\hline $\begin{array}{l}\mathrm{O}-\mathrm{C}_{\alpha} \\
\mathrm{O}-\mathrm{H}^{\alpha} \\
\mathrm{C}_{\alpha}-\mathrm{C}_{1} \\
\mathrm{C}^{\alpha}-\mathrm{H}_{1} \\
\mathrm{C}_{\alpha}-\mathrm{H}_{2} \\
\mathrm{C}_{\alpha}^{\alpha}-\mathrm{C}_{2} \\
\mathrm{C}_{1}-\mathrm{H}_{3} \\
\mathrm{C}_{1}-\mathrm{H}_{4} \\
\mathrm{C}_{2}-\mathrm{H}_{5} \\
\mathrm{C}_{2}-\mathrm{H}_{6} \\
\mathrm{C}_{2}-\mathrm{H}_{7}\end{array}$ & $\begin{array}{l}1.4253 \\
0.9595 \\
1.5119 \\
1.0929 \\
1.0946 \\
1.5215 \\
1.0913 \\
1.0907 \\
1.0870 \\
1.0901 \\
1.0883\end{array}$ & $\begin{array}{l}\mathrm{O}-\mathrm{C}_{\alpha}-\mathrm{C}_{1} \\
\mathrm{C}_{\alpha}-\mathrm{C}_{1}-\mathrm{C}_{2} \\
\mathrm{H}_{\alpha}-\mathrm{O}-\mathrm{C}^{2} \\
\mathrm{O}-\mathrm{C}_{\alpha}-\mathrm{H}_{1}^{\alpha} \\
\mathrm{O}-\mathrm{C}_{\alpha}-\mathrm{H}_{2} \\
\mathrm{C}_{\alpha}-\mathrm{C}_{1}-\mathrm{H}_{3} \\
\mathrm{C}^{\alpha}-\mathrm{C}_{1}-\mathrm{H}_{4} \\
\mathrm{C}_{1}-\mathrm{C}_{2}-\mathrm{H}_{5} \\
\mathrm{C}_{1}-\mathrm{C}_{2}-\mathrm{H}_{5} \\
\mathrm{C}_{1}-\mathrm{C}_{2}-\mathrm{H}_{5}\end{array}$ & $\begin{array}{l}107.7734 \\
112.4181 \\
108.3873 \\
110.5437 \\
110.4923 \\
108.2086 \\
108.3618 \\
110.5821 \\
110.7192 \\
111.2604\end{array}$ & $\begin{array}{l}\mathrm{O}-\mathrm{C}_{\alpha}-\mathrm{C}_{1}-\mathrm{C}_{2} \\
\mathrm{H}_{\alpha}-\mathrm{O}-\mathrm{C}_{\alpha}-\mathrm{C}_{1} \\
\mathrm{H}_{1}-\mathrm{C}_{\alpha}-\mathrm{O}-\mathrm{H}^{2} \\
\mathrm{H}_{2}-\mathrm{C}_{\alpha}-\mathrm{O}-\mathrm{H}_{\alpha} \\
\mathrm{H}_{3}-\mathrm{C}_{1}-\mathrm{C}_{\alpha}-\mathrm{O} \\
\mathrm{H}_{4}-\mathrm{C}_{1}-\mathrm{C}_{\alpha}-\mathrm{O} \\
\mathrm{H}_{5}-\mathrm{C}_{2}-\mathrm{C}_{1}-\mathrm{C}^{\alpha} \\
\mathrm{H}_{6}-\mathrm{C}_{2}-\mathrm{C}_{1}^{1}-\mathrm{C}^{\alpha} \\
\mathrm{H}_{7}-\mathrm{C}_{2}-\mathrm{C}_{1}-\mathrm{C}_{\alpha}\end{array}$ & $\begin{array}{c}62.9303 \\
-179.1282 \\
60.4521 \\
-59.2995 \\
-174.9713 \\
-59.1927 \\
-59.4009 \\
60.1902 \\
-179.8601\end{array}$ \\
\hline
\end{tabular}
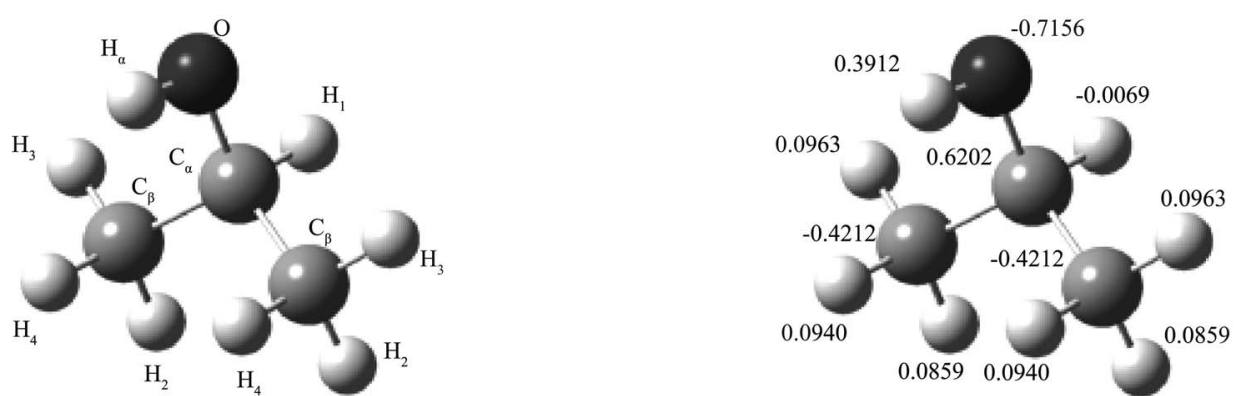

\begin{tabular}{|c|c|c|c|c|c|}
\hline Bond & Bond Length $(\AA)$ & Angle & Angle (deg) & Dihedral & Dihedral (deg) \\
\hline $\begin{array}{l}\mathrm{O}-\mathrm{C}_{\alpha} \\
\mathrm{C}_{\alpha}-\mathrm{C}_{\beta} \\
\mathrm{O}-\mathrm{H}^{\beta} \\
\mathrm{C}_{\alpha}-\mathrm{H}_{1} \\
\mathrm{C}_{\beta}^{\alpha}-\mathrm{H}_{2} \\
\mathrm{C}_{\beta}-\mathrm{H}_{3} \\
\mathrm{C}_{\beta}^{\beta}-\mathrm{H}_{4}\end{array}$ & $\begin{array}{l}1.4275 \\
1.5171 \\
0.9619 \\
1.0898 \\
1.0893 \\
1.0874 \\
1.0915\end{array}$ & $\begin{array}{l}\mathrm{O}-\mathrm{C}_{\alpha}-\mathrm{C}_{\beta} \\
\mathrm{H}_{\alpha}-\mathrm{O}-\mathrm{C}_{\alpha} \\
\mathrm{H}_{1}-\mathrm{C}_{\alpha}-\mathrm{O} \\
\mathrm{H}_{2}-\mathrm{C}_{\beta}-\mathrm{C}_{\alpha} \\
\mathrm{H}_{3}-\mathrm{C}_{\beta}-\mathrm{C}^{\alpha} \\
\mathrm{H}_{4}-\mathrm{C}_{\beta}-\mathrm{C}_{\alpha}^{\alpha}\end{array}$ & $\begin{array}{l}110.9218 \\
107.4736 \\
104.0084 \\
111.0209 \\
110.5208 \\
110.1218\end{array}$ & $\begin{array}{l}\mathrm{O}-\mathrm{C}_{\alpha}-\mathrm{C}_{-}-\mathrm{C}_{\beta} \\
\mathrm{H}_{\alpha}-\mathrm{O}-\mathrm{C}_{\alpha}-\mathrm{C}_{\beta} \\
\mathrm{H}_{1}-\mathrm{C}_{\alpha}-\mathrm{O}-\mathrm{H}_{\alpha} \\
\mathrm{H}_{2}-\mathrm{C}_{\beta}^{-}-\mathrm{C}_{\alpha}-\mathrm{O} \\
\mathrm{H}_{3}-\mathrm{C}_{\beta}-\mathrm{C}_{\alpha}^{\alpha}-\mathrm{O} \\
\mathrm{H}_{4}-\mathrm{C}_{\beta}^{-}-\mathrm{C}_{\alpha}-\mathrm{O}\end{array}$ & $\begin{array}{c}125.1652 \\
-62.5826 \\
180.0000 \\
+/-175.5156 \\
+/-54.6855 \\
+/-65.0977\end{array}$ \\
\hline
\end{tabular}

FIG. 1. Optimized geometry and ESP point charges (labeled on right-hand figure) for propanol (top) and isopropanol (bottom). second model represented the $a b$ initio energy landscapes of methanol and ethanol as well as, or arguably better than, the more traditional model of collapsing electron density information into point charges. See Ref. 1 for additional details and discussion of modeling polar molecules sans point charges.

The model shown in Eq. (2) has recently been used by several groups to regress $a b$ initio potential energy surfaces. In our previous studies we found that the modified Morse model fits potential energy landscapes significantly better than Lennard-Jones and exp-6 models.,5,6 Garrison and Sandler ${ }^{8}$ found that Gibbs ensemble simulations accurately reproduced the experimental vapor-liquid phase dome of acetylene using a site-site Morse-C6 model. Hayes et al. ${ }^{9}$ found better agreement between experimental and simulated thermodynamic data with a Morse potential model derived from an $a b$ initio methane potential energy surface than that obtained with more commonly used parameter sets and models.

Models developed from $a b$ initio calculated pair potentials are fairly recent. For example, transferable parameters for alcohols are available for OPLS (Ref. 10) and TRAPPE (Ref. 11) force field models. The parameters in these models have been regressed from experimental data to optimize them for use in simulations to predict thermophysical properties. Other models have also been developed, in which the model parameters have been tuned for specific properties.
For example, Zhang and Ely ${ }^{12}$ used an anisotropic, unitedatom, Buckingham-exponential-6 potential model with parameters optimized to pure alcohol viscosity data to simulate mixture viscosities. Boutard et al. ${ }^{13}$ used methanol and ethanol vapor-liquid equilibrium data to tune interactions for general phase equilibrium calculations involving alcohols. Models tuned with experimental data inherently contain multibody information, which can lead to higher accuracy for conditions and properties for which they have been tuned. Models obtained from $a b$ initio dimer potential energy surfaces are true pair potentials and may need multibody corrections for accurate simulations at high densities. $A b$ initio-derived molecular pair potential models can also be scaled and supplemented with polarizability to take into account multibody effects and better represent experimental results. $^{14}$

In our previous studies of small alkane dimers, ${ }^{2-7}$ we found that Eq. (2) with $z_{i}=0$ provides a reasonably good representation of the $a b$ initio potential energy surface of nonpolar dimers. Moreover, the Morse parameters obtained were found to have a relatively high degree of transferability from one alkane molecule to the next. The generic $\mathrm{C}-\mathrm{C}$, $\mathrm{C}-\mathrm{H}$, and $\mathrm{H}-\mathrm{H}$ interaction parameters regressed from dimer potential energy landscapes for neopentane, isopropane, propane, and ethane are referred to here as NIPE values, ${ }^{3}$ an acronym for the surfaces used in the regression.

An obvious advantage of modeling the energy land- 

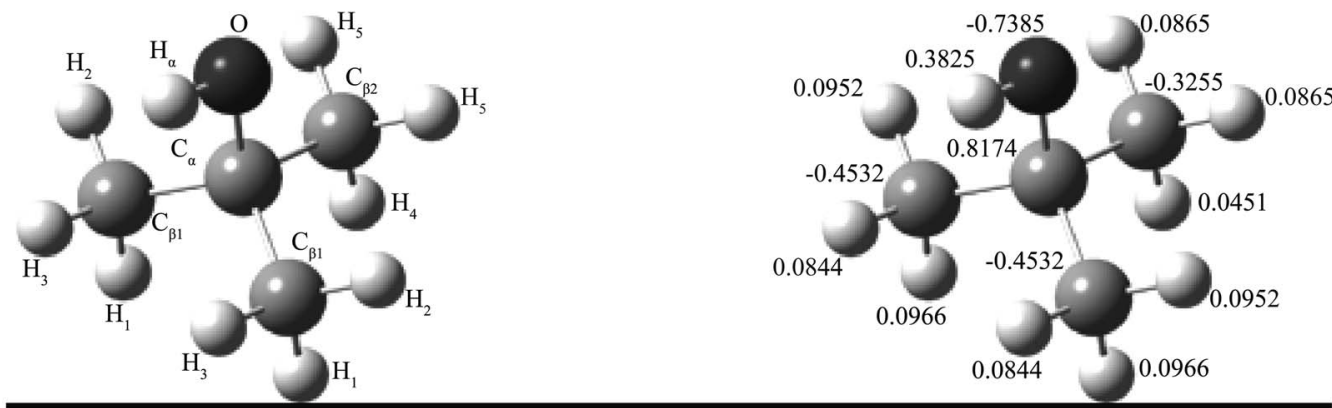

\begin{tabular}{|c|c|c|c|c|c|}
\hline Bond & Bond Length $(\AA)$ & Angle & Angle (deg) & Dihedral & Dihedral (deg) \\
\hline $\begin{array}{l}\mathrm{O}-\mathrm{C}_{\alpha} \\
\mathrm{C}_{\alpha}-\mathrm{C}_{\beta 1}^{\alpha} \\
\mathrm{C}_{\alpha}^{\alpha}-\mathrm{C}_{\beta 2} \\
\mathrm{O}-\mathrm{H}_{\alpha} \\
\mathrm{C}_{\beta}-\mathrm{H}_{1} \\
\mathrm{C}_{\beta 1}-\mathrm{H}_{2} \\
\mathrm{C}_{\beta 1}-\mathrm{H}_{3} \\
\mathrm{C}_{\beta 2}-\mathrm{H}_{4} \\
\mathrm{C}_{\beta 2}-\mathrm{H}_{5}\end{array}$ & $\begin{array}{l}1.4336 \\
1.5213 \\
1.5161 \\
0.9622 \\
1.0896 \\
1.0884 \\
1.0911 \\
1.0888 \\
1.0884\end{array}$ & $\begin{array}{l}\mathrm{O}-\mathrm{C}_{\alpha}-\mathrm{C}_{\beta 1} \\
\mathrm{O}-\mathrm{C}_{\alpha}-\mathrm{C}_{\beta 2} \\
\mathrm{H}_{\alpha}-\mathrm{O}-\mathrm{C}_{\alpha} \\
\mathrm{H}_{1}-\mathrm{C}_{\beta 1}-\mathrm{C}^{0} \\
\mathrm{H}_{2}-\mathrm{C}_{\beta 1}-\mathrm{C}^{0} \\
\mathrm{H}_{3}-\mathrm{C}_{\beta 1}-\mathrm{C}^{0} \\
\mathrm{H}_{4}-\mathrm{C}_{\beta 2}-\mathrm{C}^{0} \\
\mathrm{H}_{5}-\mathrm{C}_{\beta 2}-\mathrm{C}^{0}\end{array}$ & $\begin{array}{l}109.7066 \\
104.8898 \\
107.7068 \\
110.9787 \\
110.0655 \\
110.5664 \\
110.5518 \\
110.0857\end{array}$ & 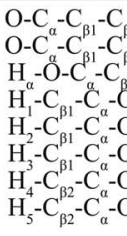 & $\begin{array}{c}-119.0438 \\
121.9124 \\
60.9562 \\
+/-177.6286 \\
+/-57.1209 \\
+/-62.6552 \\
180.0000 \\
+/-59.7667\end{array}$ \\
\hline
\end{tabular}
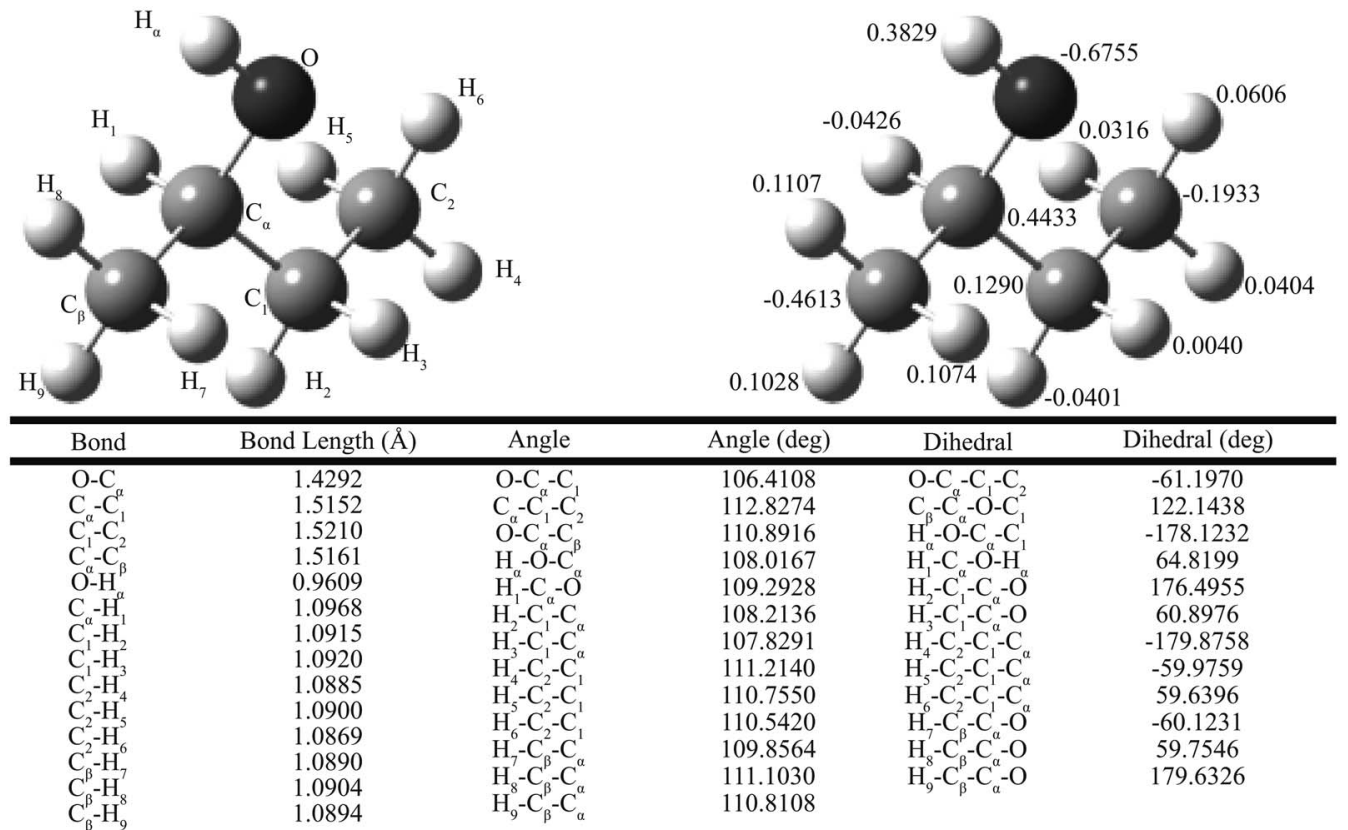

FIG. 2. Optimized geometry and ESP point charges (labeled on right-hand figure) for $t$-butanol (top) and sec-butanol (bottom).

scapes with Eqs. (1) and (2) is the reduction of independent spatial variables required to define the relative orientations of the monomers; only interatomic distances are required to obtain the potential energy for any given dimer configuration. The viability of such models in simulation studies is dependent only on how well it reproduces the actual potential energy surface. In this study we both examine the ability of the model to reproduce the $a b$ initio dimer landscapes and the extent to which the model parameters can be taken as independent of the alcohol dimer from which they were regressed. Such parameter transferability suggests some physical underpinning of the model and the possible use of the interatomic parameters for use in predicting other alcohol dimer potentials. In conjunction with the companion paper, these surfaces also provide opportunity to qualitatively examine the effect of additional $-\mathrm{CH}_{x}-$ character and structural branching on alcohol dimer interactions.

\section{COMPUTATIONAL DETAILS}

As in the companion paper, all calculations were made with MP2/6-311+G(2df,2pd) using GAUSSIAN 98. ${ }^{15}$ The level of theory and basis set size used in this study were the same in our previous studies in order to maintain consistency with those studies. That is, the transferable site-site interactions regressed from these combined studies all represent the landscapes generated with MP2/6-311+G(2df,2pd). Sev-
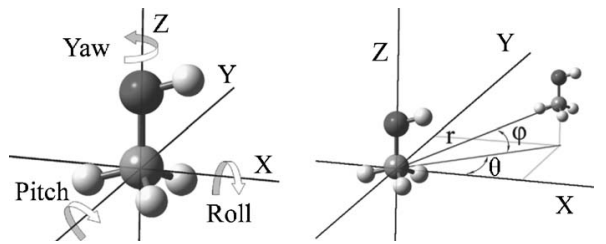

FIG. 3. Illustration of yaw, pitch, roll, $r, \theta$, and $\varphi$ coordinates to describe dimer approach routes (using methanol monomers to simplify diagram). 
TABLE I. Propanol routes in terms of the approach axis (gray line) as defined by yaw, pitch, roll, $\theta$, and $\phi$ coordinates. Multiple values represent the coefficients in Eq. (3) for yaw, pitch, roll, and $\theta$ or Eq. (4) for $\phi$.

\begin{tabular}{|c|c|c|c|c|c|c|}
\hline Approach & Number & Yaw & Pitch & Roll & $\theta$ & $\phi$ \\
\hline & 1 & 181.89 & -71.59 & -2.62 & 179.13 & 35.806 \\
\hline & 2 & 358.22 & 17.42 & 179.73 & 179.13 & $\begin{array}{r}-2.3746 \\
2.1406 \\
0.5796\end{array}$ \\
\hline 4 & 3 & 178.25 & 0.00 & 180.00 & -0.87 & $\begin{array}{r}-0.4247 \\
0.0018 \\
0.9999 \\
-1.4119\end{array}$ \\
\hline$x+3 x$ & 4 & 178.26 & 0.00 & -180.00 & -0.87 & $\begin{array}{l}2.6105 \\
0.3135\end{array}$ \\
\hline & 5 & 180.64 & 54.16 & 1.24 & -0.87 & $\begin{array}{c}0.7073 \\
-0.0082 \\
-0.9996\end{array}$ \\
\hline & 6 & 180.00 & -16.79 & -0.26584 & 179.128 & $\begin{array}{r}-0.4112 \\
0.9475 \\
0.5849\end{array}$ \\
\hline & & 0.0128 & 0.0015 & 0.0068 & 0.0248 & 3.5144 \\
\hline & 7 & -0.8265 & -0.9175 & -0.9396 & 0.4245 & -2.4865 \\
\hline & & 217.74 & 21.047 & -70.617 & 118.98 & 0.3818 \\
\hline & 8 & 178.26 & 0.00 & 180.00 & 0.00 & -90.00 \\
\hline 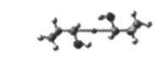 & 9 & 178.26 & 0.00 & -180.00 & -0.87 & 18.39 \\
\hline की से & 10 & 0.00 & -0.60 & 0.00 & -0.87 & $\begin{array}{c}-1 \mathrm{E}-05 \\
0.0092 \\
0.3154\end{array}$ \\
\hline & 11 & $\begin{array}{c}-0.0107 \\
0.2163 \\
320.05\end{array}$ & $\begin{array}{c}-0.0092 \\
1.2223 \\
23.159\end{array}$ & $\begin{array}{c}-0.0071 \\
-0.5527 \\
75.638\end{array}$ & $\begin{array}{c}0.1163 \\
-1.9975 \\
140.83\end{array}$ & $\begin{array}{c}2.7614 \\
-1.6968 \\
0.363 \\
6 \mathrm{E}-05\end{array}$ \\
\hline 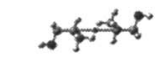 & 12 & 178.26 & 0.00 & 180.00 & 179.13 & $\begin{array}{l}-0.0183 \\
-0.3257\end{array}$ \\
\hline to & 13 & $\begin{array}{c}-0.0177 \\
1.1527 \\
134.01\end{array}$ & $\begin{array}{r}0.0005 \\
0.7717 \\
-34.383\end{array}$ & $\begin{array}{c}0.0112 \\
-1.2728 \\
122.68\end{array}$ & $\begin{array}{l}0.0686 \\
-1.043 \\
134.66\end{array}$ & $\begin{array}{r}4.8967 \\
-2.1607 \\
0.3808\end{array}$ \\
\hline$+6+3$ & 14 & $\begin{array}{l}0.0021 \\
1.2178\end{array}$ & $\begin{array}{r}0.0189 \\
-1.9817\end{array}$ & $\begin{array}{l}-0.0024 \\
-0.8837\end{array}$ & $\begin{array}{c}0.0582 \\
-0.78\end{array}$ & $\begin{array}{r}4.9335 \\
-3.6937\end{array}$ \\
\hline & & 85.371 & 54.523 & -129.43 & 131.53 & $\begin{array}{l}0.3979 \\
0.9909\end{array}$ \\
\hline कर करे & 15 & 181.94 & -71.56 & -2.68 & 179.13 & $\begin{array}{c}-0.016 \\
-0.9991 \\
-0.3107\end{array}$ \\
\hline$+x+2$ & 16 & 178.26 & 0.00 & -180.00 & -0.87 & $\begin{array}{r}1.2879 \\
0.3152 \\
-0.3069\end{array}$ \\
\hline $40+4$ & 17 & 0.00 & -0.60 & 0.00 & -0.87 & $\begin{array}{c}1.295 \\
0.3153\end{array}$ \\
\hline$+1+6$ & 18 & $\begin{array}{r}-0.0299 \\
2.3652 \\
278.95\end{array}$ & $\begin{array}{c}0.0195 \\
-0.1772 \\
-53.226\end{array}$ & $\begin{array}{c}0.0273 \\
-2.6675 \\
170.97\end{array}$ & $\begin{array}{l}0.1881 \\
-4.331 \\
162.69\end{array}$ & $\begin{array}{r}2.8903 \\
-1.1064 \\
0.3501\end{array}$ \\
\hline
\end{tabular}

eral studies found that the effect of electron correlation beyond an MP2 treatment was not large and that accurate potential energy surfaces can be obtained from MP2 calculations with reasonably large basis sets containing multiple polarization functions. ${ }^{16-18}$ Our own results with methane $^{2}$ showed that energies calculated with MP2/6-311 $+\mathrm{G}(2 d f, 2 p d)$ differed from those calculated with MP4/augcc-pVTZ by less than $0.04 \mathrm{kcal} / \mathrm{mol}$.

Optimized geometries of the isolated monomers and model point charges obtained from the ESP method are shown in Fig. 1 for propanol and isopropanol and in Fig. 2 for $t$-butanol and sec-butanol. These geometries were used without relaxation to determine $a b$ initio data for unique dimer orientations.

All potential energies of the dimer pair were counter- poise corrected. Potential energy scans were performed for the dimers along routes of fixed relative monomer orientations. The routes were defined in terms of an approach axis along which the distance between the two monomers was varied. Figure 3 defines the geometrical terms that are used throughout this paper to define the approach routes. In all cases, the origin for the coordinate system for each monomer is the primary alcohol $\mathrm{C}$ atom (labeled $\mathrm{C}_{\alpha}$ ). The standard monomer orientation, depicted in the left-hand drawing of Fig. 3, places the $\mathrm{C}_{\alpha}-\mathrm{O}$ bond along the $z$ axis with the $\mathrm{O}-\mathrm{H}$ bond parallel to the $x$ axis. Dimer route orientations are defined in terms of the yaw, pitch, and roll angles of the second monomer relative to the standard orientation in which the first monomer is fixed. As shown in Fig. 3, yaw $\left(0^{\circ} \leqslant\right.$ yaw $<360^{\circ}$ ) represents a right-hand rotation about the $z$ axis, 
TABLE II. Isopropanol routes in terms of the approach axis (gray line) as defined by yaw, pitch, roll, $\theta$, and $\phi$ coordinates. Multiple values represent the coefficients in Eq. (4) for $\phi$.

\begin{tabular}{|c|c|c|c|c|c|c|}
\hline Approach & Number & Yaw & Pitch & Roll & $\boldsymbol{\theta}$ & $\phi$ \\
\hline بs & 1 & 180.00 & -72.51 & 0.00 & -180.00 & 36.26 \\
\hline & 2 & 180.00 & -72.51 & 0.00 & 0.00 & -36.26 \\
\hline & 3 & 0.00 & 0.03 & 0.00 & -180.00 & 36.26 \\
\hline & 4 & 0.076 & 53.72 & 0.05 & -180.00 & $\begin{array}{r}-0.4144 \\
0.9328 \\
0.5912\end{array}$ \\
\hline 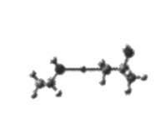 & 5 & 62.58 & -17.75 & 0.00 & -180.00 & $\begin{array}{c}-0.4563 \\
0.9829 \\
0.5913\end{array}$ \\
\hline 90 & 6 & 0.07 & -0.03 & 180.00 & 62.58 & -89.93 \\
\hline & 7 & 260.67 & -25.86 & 110.69 & 62.58 & $\begin{array}{r}0.0006 \\
-0.0602 \\
-0.3177\end{array}$ \\
\hline & 8 & 305.19 & -0.03 & -180.00 & 62.58 & $\begin{array}{l}0.0026 \\
-0.1204 \\
-0.3177\end{array}$ \\
\hline+3 & 9 & 180.13 & -72.51 & -0.10 & 0.00 & $\begin{array}{r}-0.3034 \\
1.3044 \\
0.2999\end{array}$ \\
\hline 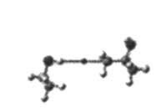 & 10 & 242.60 & -1.04 & 0.00 & 0.00 & $\begin{array}{c}-0.3263 \\
1.3635 \\
0.3001\end{array}$ \\
\hline sta & 11 & 0.00 & -53.74 & 0.00 & -180.00 & $\begin{array}{r}-0.0131 \\
-0.1698 \\
0.5915\end{array}$ \\
\hline
\end{tabular}

pitch $\left(-90^{\circ} \leqslant\right.$ pitch $\left.\leqslant 90^{\circ}\right)$ represents a right-hand rotation about the $y$ axis, and roll $\left(-180^{\circ} \leqslant\right.$ roll $\left.\leqslant 180^{\circ}\right)$ represents a right-hand rotation about the $x$ axis. The relative spatial location of each monomer origin is characterized by the spherical coordinate triplet $(r, \theta, \phi)$ for the vector from the first monomer origin to the second. This is depicted in the righthand diagram of Fig. 3 , where it can be seen that $\theta\left(-180^{\circ}\right.$ $\leqslant \theta<180^{\circ}$ ) specifies the angle between the origin-to-origin vector and the $x$ axis, $\phi\left(-90^{\circ} \leqslant \phi \leqslant 90^{\circ}\right)$ specifies the azimuthal angle between the vector and the $x-y$ plane, and $r$ specifies the distance between the origins.

The approach routes for the four dimers are defined in Tables I-IV. The thumbnail picture of the route shown in the left column depicts the approach axis (line) between the monomers. The central site in these thumbnails, represented by a small sphere, is a dummy site used in the scans to vary $r$, the distance between the positions of the two $\mathrm{C}_{\alpha}$ nuclei. The orientation of the second monomer relative to the first does not change in many of the routes; in this case the yaw, pitch, and roll of the second molecule do not vary with $r$, and a single value appears in the columns of Tables I-IV for the yaw, pitch, and roll of the second molecule. In all cases, the first molecule is maintained in the standard orientation shown in Fig. 3. For those cases in which the relative orientation of the second molecule changes with the approach distance $r$, yaw, pitch, and roll have been parametrized in terms of $r$ and three entries appear in these columns instead of a fixed angle. These entries correspond to the $a, b$, and $c$, respectively, in the correlation 
TABLE III. $t$-Butanol routes in terms of the approach axis (gray line) as defined by yaw, pitch, roll, $\theta$, and $\phi$ coordinates. Multiple values represent the coefficients in Eq. (4) for $\phi$.

\begin{tabular}{|c|c|c|c|c|c|c|}
\hline Approach & Number & Yaw & Pitch & Roll & $\theta$ & $\phi$ \\
\hline & 1 & 180.00 & -72.27 & 0.00 & -180.00 & 36.15 \\
\hline & 2 & 0.00 & 0.00 & 0.00 & -180.00 & 36.15 \\
\hline & 3 & 0.00 & 72.29 & 180.00 & -180.00 & $\begin{array}{r}-1.9555 \\
1.9462 \\
0.5857\end{array}$ \\
\hline & 4 & 0.00 & 2.817 & 0.00 & 0.00 & $\begin{array}{c}-0.3019 \\
1.3044 \\
0.304\end{array}$ \\
\hline & 5 & 0.00 & -72.26 & 0.00 & 0.00 & $\begin{array}{r}-0.3043 \\
1.3051 \\
0.3039\end{array}$ \\
\hline & 6 & 359.94 & 75.11 & 179.92 & 0.00 & -90.00 \\
\hline ?े & 7 & 180.00 & 0.00 & 180.00 & -180.00 & -14.89 \\
\hline & 8 & 180.00 & 0.00 & 180.00 & 0.00 & -90.00 \\
\hline & 9 & 180.00 & 51.04 & 180.00 & -180.00 & $\begin{array}{c}-0.4127 \\
0.9381 \\
0.5897\end{array}$ \\
\hline & 10 & 0.00 & 0.00 & 0.00 & 0.00 & 90.00 \\
\hline & 11 & 180.00 & 53.86 & 0.030 & -180.00 & $\begin{array}{c}-0.4173 \\
0.9393 \\
0.5896\end{array}$ \\
\hline 8 & 12 & 0.00 & 18.46 & 180.00 & 0.00 & $\begin{array}{r}-1.2851 \\
2.4714 \\
0.3004\end{array}$ \\
\hline & 13 & 180.00 & 0.00 & 180.00 & -180.00 & $\begin{array}{l}-3.723 \\
2.6563 \\
0.5823\end{array}$ \\
\hline
\end{tabular}

$\left[\begin{array}{c}\text { yaw } \\ \text { pitch } \\ \text { roll } \\ \theta\end{array}\right]=a r^{2}+b r+c$

Likewise, $\theta$ and $\phi$, defining the relative angles of the originto-origin vector from the first monomer to the second, have been parametrized in terms of the separation distance $r$. The triple entries in Tables I-IV for $\theta$ are the coefficients $a, b$, and $c$ in Eq. (3); the entries for $\phi$ correspond to the coefficients $a, b$, and $c$, respectively, in

$$
\phi=\sin ^{-1}\left(\frac{a}{r^{2}}+\frac{b}{r}+c\right) .
$$

Dimer energies were calculated at 15 different separation distances $r$ along each route for a combined total of 735 counterpoise-corrected values: 270 for the propanol surface, 165 for the isopropanol surface, 195 for the $t$-butanol surface, and 105 for the sec-butanol surface.

\section{POTENTIAL ENERGY LANDSCAPES}

Results of the dimer potential energies for each of the routes are shown in Figs. 4-7. Route numbers defined in Tables I-IV are shown in the legends, but the routes are loosely grouped in the figures by the expected dominant sitesite interaction. Routes grouped together tend to bring similar sites toward each other along the approach axis. For convenience, we will refer to routes in Figs. 4-7 using the nomenclature $\mathrm{Cr}$ where $C$ represents the compound abbreviation $(\mathrm{P}=$ propanol, $\mathrm{I}=$ isopropanol, $\mathrm{T}=t$-butanol, and $\mathrm{S}$ =sec-butanol) and $r$ represents the route number. Thus, P2 represents propanol route $2, \mathrm{~S} 3$ represents sec-butanol route 3 , etc.

As one might expect, the dominant attractive routes are those that bring the $\mathrm{O}$ and $\mathrm{H}_{\alpha}$ atoms together for hydrogen bonding. The deep attractive wells for P2, P3, I3, I11, T12, and $\mathrm{S} 4$ are clearly dominated by the $\mathrm{O}-\mathrm{H}_{\alpha}$ interaction. These strong $\mathrm{O}-\mathrm{H}_{\alpha}$ attractive potential wells arise primarily from the Hartree-Fock portion of the $a b$ initio calculation 
TABLE IV. sec-Butanol routes in terms of the approach axis (gray line) as defined by yaw, pitch, roll, $\theta$, and $\phi$ coordinates. Multiple values represent the coefficients in Eq. (3) for yaw, pitch, roll, and $\theta$ or Eq. (4) for $\phi$.

\begin{tabular}{|c|c|c|c|c|c|c|}
\hline Approach & Number & Yaw & Pitch & Roll & $\theta$ & $\phi$ \\
\hline$x$ & 1 & 180.00 & -72.00 & 0.00 & -180.00 & 35.99 \\
\hline$x$ & 2 & 0.00 & 0.00 & 0.00 & -180.00 & 35.99 \\
\hline $4 x$ & 3 & 0.00 & -54.03 & 0.00 & -180.00 & $\begin{array}{c}-0.0121 \\
-0.164 \\
0.5877\end{array}$ \\
\hline+5 & 4 & 0.00 & 17.97 & 180.00 & -180.00 & $\begin{array}{c}-2.3937 \\
2.141 \\
0.5823\end{array}$ \\
\hline से से & 5 & 180.00 & 0.00 & 180.00 & 0.00 & 18.02 \\
\hline 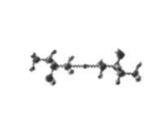 & 6 & 291.92 & 0.00 & 180.00 & 55.98 & $\begin{array}{c}0.0004 \\
0.0426 \\
-0.3711\end{array}$ \\
\hline 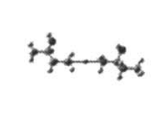 & 7 & $\begin{array}{c}0.0228 \\
-1.5095 \\
363.82\end{array}$ & $\begin{array}{l}0.0009 \\
0.0224 \\
23.033\end{array}$ & $\begin{array}{c}0.0036 \\
-0.0157 \\
17.851\end{array}$ & $\begin{array}{c}-0.1417 \\
-0.4241 \\
0.8274\end{array}$ & $\begin{array}{c}0.3956 \\
1.108 \\
-0.3703\end{array}$ \\
\hline
\end{tabular}

and are dominated by strong permanent charge distribution within the monomers. Figures 1 and 2 show that increased branching at the $\mathrm{C}_{\alpha}$ site produces larger negative charges on the $\mathrm{O}$ atom, consistent with the corresponding deeper potential wells (stronger hydrogen bonds) of the direct $\mathrm{O}-\mathrm{H}_{\alpha}$ routes in the order $\mathrm{P} 2, \mathrm{I} 11, \mathrm{~S} 4$, and $\mathrm{T} 12$.

Routes P1, I1, T1, and S1 all feature the approach of the two $\mathrm{O}$ atoms together. The $\mathrm{I} 1$ and $\mathrm{T} 1$ routes are entirely repulsive as one might suspect from the electrostatics. S2 has a substantial attractive region at reasonably close distances despite the $\mathrm{O}-\mathrm{O}$ approach. The two monomers are oriented in the same direction, so as they approach each other along this route there is considerable dispersion attractions from the alkyl chains before the two $\mathrm{O}$ atoms approach each other close enough for their mutual repulsion to impact the potential. Dispersion interactions between the alkyl chains also produce the attractive wells in routes $\mathrm{P} 1$ and $\mathrm{S} 1$. In this case, the ends of the two alkyl chains are directed toward each other, creating early opportunity for dispersion attractions as the monomers approach each other. We were surprised that P16 and T13 were entirely repulsive because both orientations appear to create the opportunity for double $\mathrm{O}-\mathrm{H}_{\alpha}$ interactions, but the repulsions of the more direct $\mathrm{C}_{\alpha}-\mathrm{H}_{\alpha}$ interaction for $\mathrm{P} 16$ and the $\mathrm{O}-\mathrm{O}$ interaction for $\mathrm{T} 13$ dominate. The repulsive nature of $\mathrm{P} 4$ is due to the head-to-head approach of the $\mathrm{H}_{\alpha}$ atoms on the two monomers, both of which have a strong positive partial charge.

Routes P5, I4, T10, and T11 are of type $\mathrm{O}-\mathrm{C}_{\alpha}$ and exhibit deep attractive wells. The trends in these routes are consistent with the ESP charges listed in Figs. 1 and 2. The charges on the $\mathrm{C}_{\alpha}$ atom are $0.2117,0.6202$, and 0.8174 for propanol, isopropanol, and $t$-propanol, respectively, and the corresponding attractive minima for $\mathrm{P} 5, \mathrm{I} 4$, and $\mathrm{T} 10$ are $-1.4,-1.8$, and $-2.5 \mathrm{kcal} / \mathrm{mol}$. Routes P6, I5, and T9 also bring an $\mathrm{O}$ toward a carbon atom, but toward the $\mathrm{C}$ atom attached to the $\mathrm{C}_{\alpha}$ atom, which we designate as $\mathrm{C}_{1}$ in propanol (and ethanol) and as $\mathrm{C}_{\beta}$ in isopropanol and $t$-butanol. These routes also exhibit relatively strong attractive potential wells, but the minima are not as deep as those for the routes dominated by the $\mathrm{O}-\mathrm{C}_{\alpha}$ interaction. Again the relative magnitudes of these attractive wells are consistent with the ESP charges on these atoms. The minima in P5 and P6 are approximately equal as are the ESP charges on $\mathrm{C}_{\alpha}$ and $\mathrm{C}_{1}$ in propanol. However, the charges on the $\mathrm{C}_{\beta}$ atoms in isopropanol and $t$-butanol are negative (which is why we distinguish them as $\mathrm{C}_{\beta}$ instead of $\mathrm{C}_{1}$ ) and the corresponding well depths for I5 and T9 are significantly attenuated relative to I4, T10, and T11.

The significant attractive well at about $3.8 \AA$ on P9 followed by a repulsive hump at about $6 \AA$ is interesting. This behavior seems to be due to $\mathrm{C}_{\alpha}-\mathrm{C}_{\alpha}$ repulsions at the larger distances, where the $\mathrm{O}-\mathrm{H}$ interactions are oriented too far away to contribute significantly. At closer distances the much deeper $\mathrm{O}-\mathrm{H}$ well and the $\mathrm{C}-\mathrm{H}_{\alpha}$ attractions (see P18) successfully overcome the $\mathrm{C}_{\alpha}-\mathrm{C}_{\alpha}$ repulsions, though they are not directly emphasized by this approach route. I2, T5, S1, and S5 also show small repulsions at larger $r$ values followed by attractive wells at closer distances. Again competing interactions effective at different $r$ values are likely the explanations of this behavior. For example, the $\mathrm{O}-\mathrm{O}$ repulsions likely produce the longer-range repulsions in I2 and S1, while the dispersion interactions from the alkyl groups become effective at shorter $\mathrm{C}_{\alpha}-\mathrm{C}_{\alpha}$ distances.

The attractive well for $\mathrm{I} 3$ is about half that of direct 

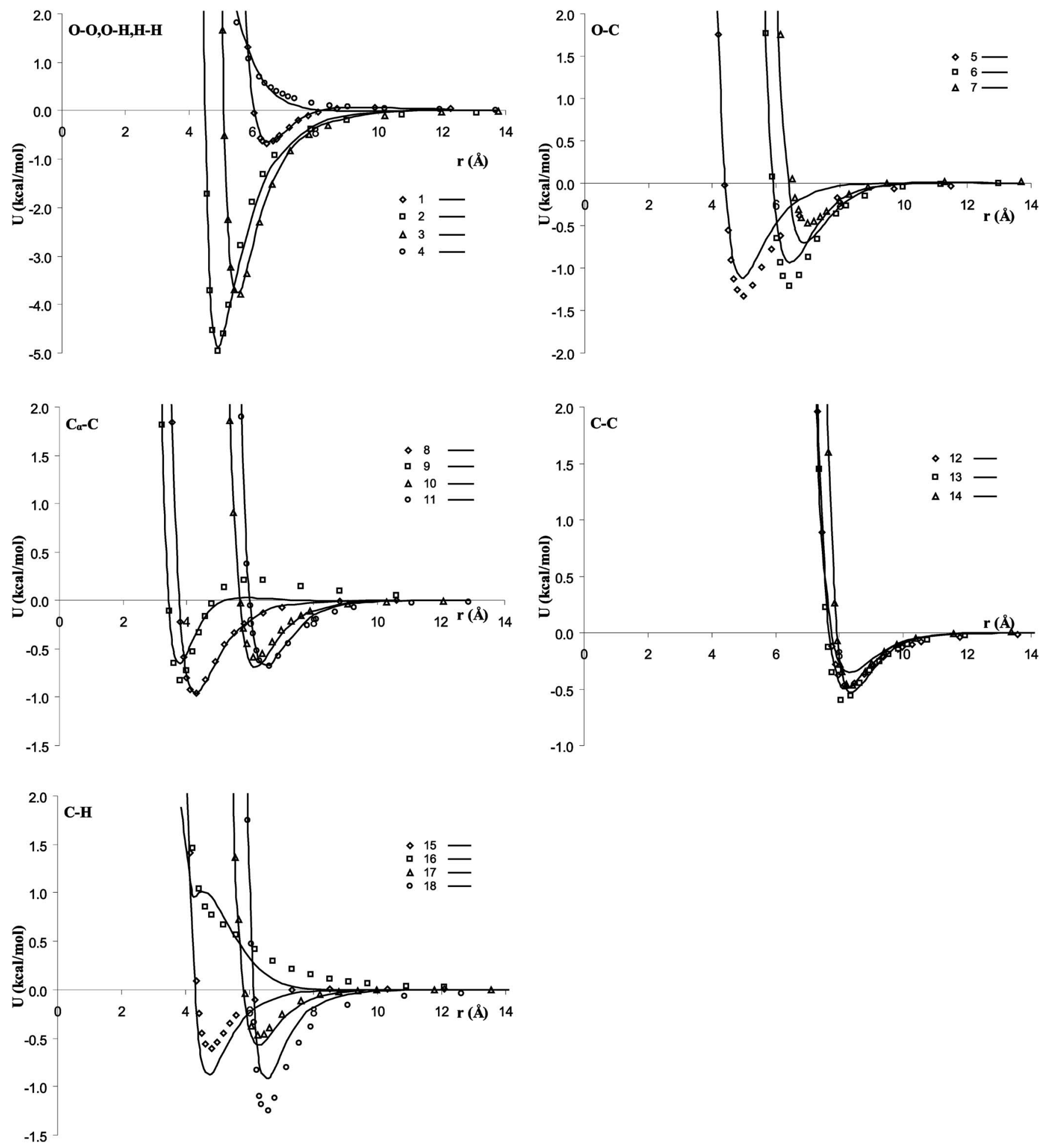

FIG. 4. Dimer energies for propanol as a function of distance between $\mathrm{C}_{\alpha}$ monomer sites from $a b$ initio calculations (points) and from the site-site model without point charges (lines).

hydrogen bond interactions and considerably broader. In spite of the approach axis through the two $\mathrm{O}$ atoms, this orientation permits a pair of longer-range $\mathrm{O}-\mathrm{H}_{\alpha}$ interactions to compete with the $\mathrm{O}-\mathrm{O}$ repulsion.

The $\mathrm{C}-\mathrm{C}$ routes (P12-P14, I6-I8, T6-T8, and S5-S7) are characteristic of dispersion interactions, in which electron correlation provides the main attractive part of the potential. These routes are very similar in appearance to those obtained in our alkane dimer studies, and this similarity suggests extending the NIPE model parameters developed from those studies to $\mathrm{C}$ interactions.

\section{PAIRWISE ADDITIVE ATOMIC POTENTIALS}

To model the potential energy surfaces using Eqs. (1) and (2), interaction sites are located at each atomic center. As in the companion paper for methanol and ethanol, a satellite 

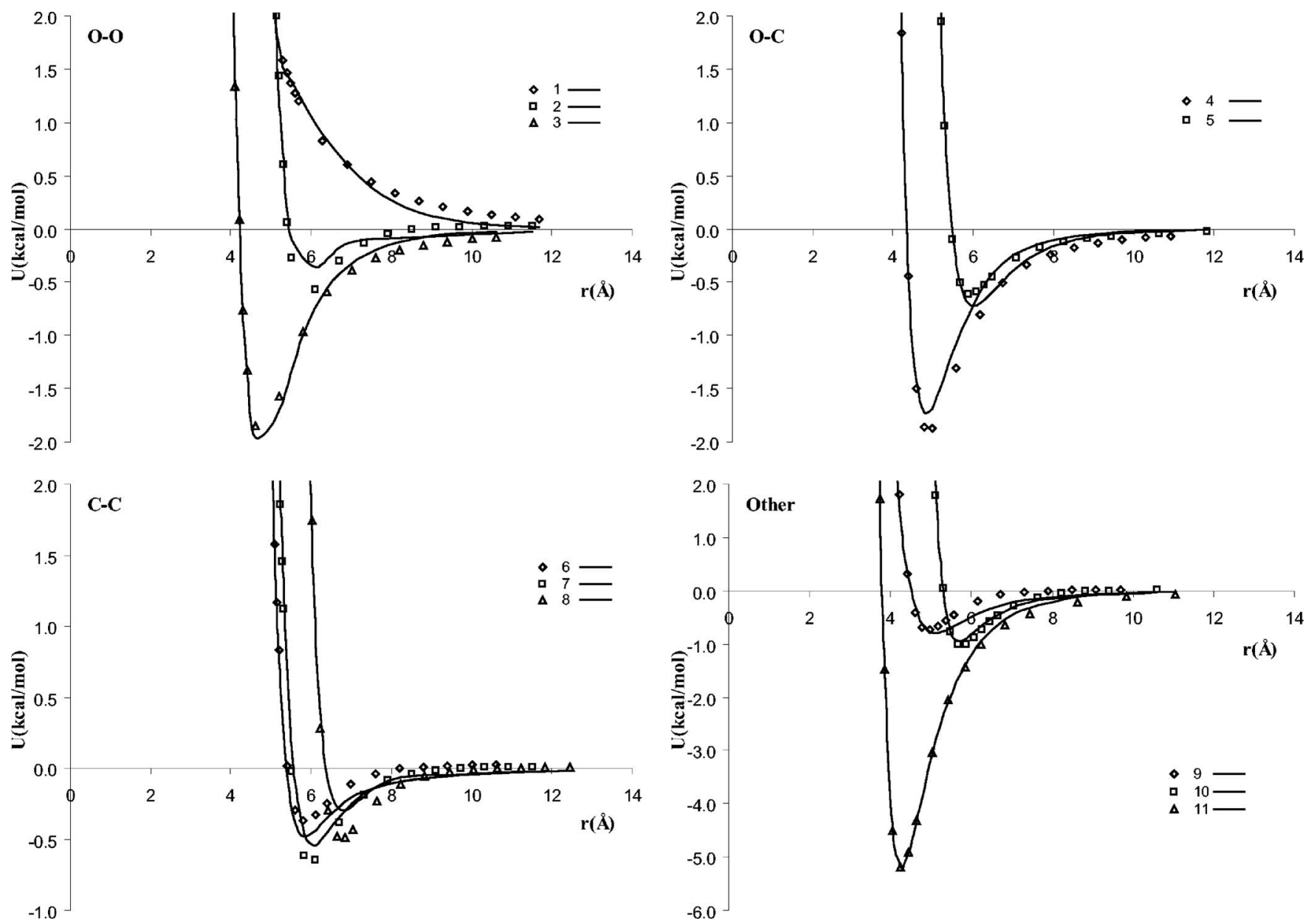

FIG. 5. Dimer energies for isopropanol as a function of distance between $\mathrm{C}_{\alpha}$ monomer sites from $a b$ initio calculations (points) and from the site-site model without point charges (lines).

site $\mathrm{X}$ was placed on the vector bisecting the $\mathrm{C}_{\alpha}-\mathrm{O}-\mathrm{H}_{\alpha}$ angle of the alcohol, but on the side of the $\mathrm{O}$ opposite the $\mathrm{C}_{\alpha}-\mathrm{O}$ and $\mathrm{O}-\mathrm{H}_{\alpha}$ bonds, to represent the off-center high electron density of the electron pairs on the $\mathrm{O}$ atom. All interactions with the satellite site were assumed to be zero except for $\mathrm{H}_{\alpha}-\mathrm{X}$ and $\mathrm{X}-\mathrm{X}$. The $\mathrm{H}_{\alpha}-\mathrm{X}$ interaction was modeled with Eq. (2), but the $\mathrm{X}-\mathrm{X}$ interaction was simplified to a purely repulsive interaction modeled with

$$
u_{\mathrm{XX}}=B_{\mathrm{XX}} \exp \left(-C_{\mathrm{XX}} r_{\mathrm{XX}}\right) .
$$

Values of the parameters $B_{\mathrm{XX}}$ and $C_{\mathrm{XX}}$ (as well as the location of the $\mathrm{X}$ site in terms of the $\mathrm{O}-\mathrm{X}$ distance) were regressed from the $a b$ initio potential landscapes simultaneously with the site-site parameters of Eq. (2).

The purpose of representing the potential energy landscapes with site-site models is to provide a mathematical parametrization of the surfaces useful for molecular simulations. Such mathematical models are particularly useful if the site-site interactions are transferable between molecules because then the model can be used as a predictive equation for other molecules whose energy landscapes might also be modeled by the same set of site-site interactions.

Amongst the many site-site models that could be used, Eqs. (1) and (2) maintain consistency with the previous NIPE model that has been developed for alkanes and has shown considerable transferability. However, the most com- mon representation of atom-atom dispersion interactions is with an $r^{-6}$ term because this is the leading term obtained from long-range perturbation theory when used in conjunction with a multipole expansion. ${ }^{19}$ Accordingly, the dispersion energy is often written as a power series in $r^{-n}$, where $n=6,8,10, \ldots$. The singularity as $r$ approaches zero is incorrect and so damping functions, usually of an exponential nature in $r$ (see, for example, Ref. 20), are used to allow an $r^{-6}$ limit at infinite distance while suppressing the singularity at $r=0$. This series is unfortunately nonconvergent (or asymptotically convergent ${ }^{19}$ ). In the model represented by Eqs. (1) and (2), the molecule-molecule interactions are a linear combination of the many exponentials representing the atomatom interactions and therefore can reproduce a variety of $r$-dependent behaviors, as shown in Figs. 4-7. However, individual atom-atom intermolecular potentials do not include the more traditional $r^{-6}$ behavior, nor is there any theoretical basis for an exponential decay. These atom-atom interactions are a means to an end and one should not attribute too much physical significance to them individually. For example, there is some evidence that the spherical or isotropic approximation used here and in most atom-atom interaction models can be poor. ${ }^{12}$ In this pragmatic view, representation of the energy landscape by the model and the model's potential for transferability is sufficient. That is, agreement be- 


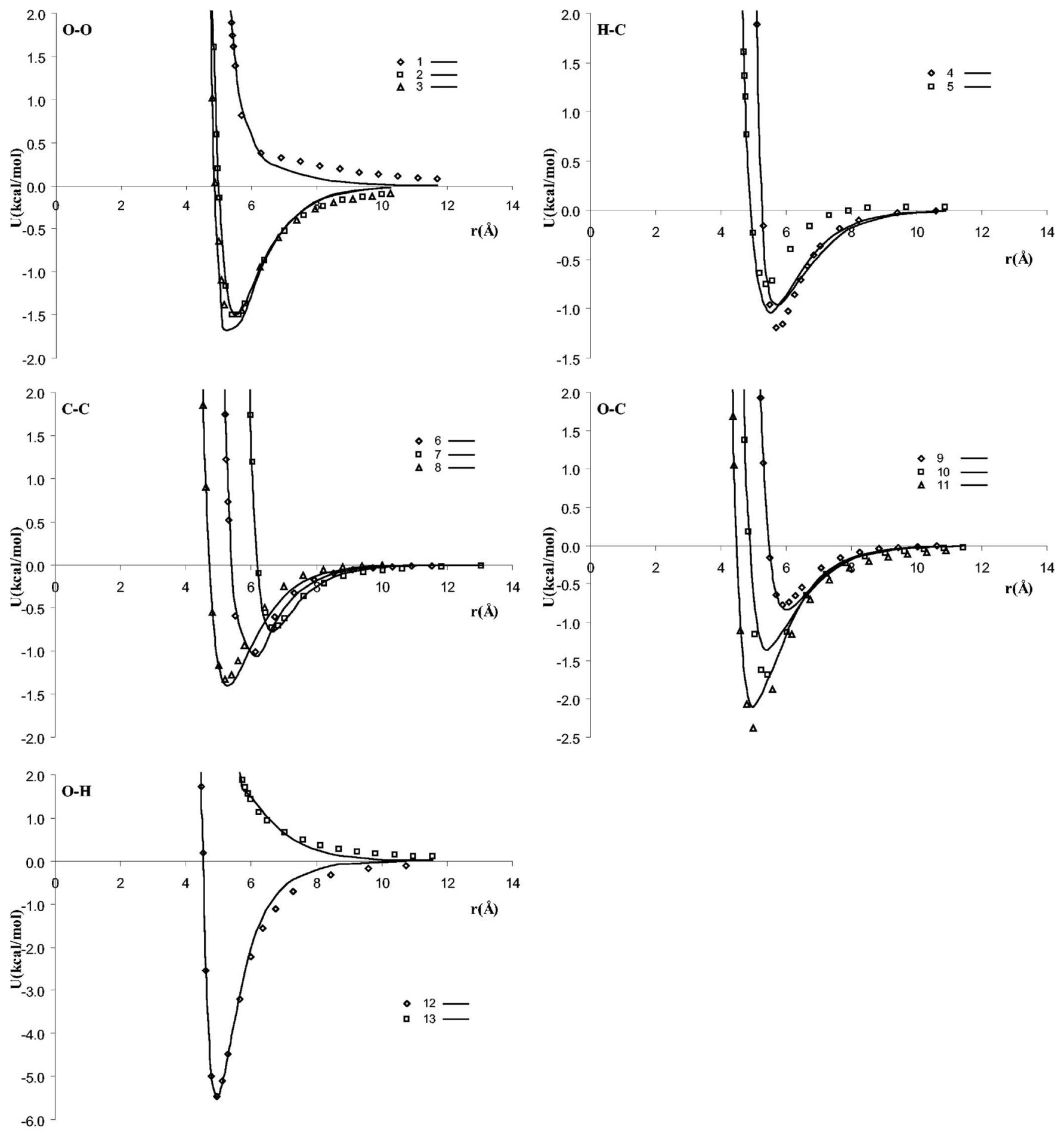

FIG. 6. Dimer energies for $t$-butanol as a function of distance between $\mathrm{C}_{\alpha}$ monomer sites from $a b$ initio calculations (points) and from the site-site model without point charges (lines).

tween the model and the ab initio potentials over intermolecular distances where the potential differs from zero more than the uncertainty of the calculations is the prime concern. Higher-level calculations and larger basis sets would likely be required to more accurately investigate the smaller potentials at larger separation distances, which Eqs. (1) and (2) may not adequately represent.

To maintain consistency and transferability with the NIPE site-site interactions developed for alkyl sites, all C atoms for which the absolute value of the ESP charge was less than 0.3 and all $\mathrm{H}$ atoms except $\mathrm{H}_{\alpha}$ were modeled as NIPE sites. With this definition, the model's set of interacting sites for all alcohols contains seven members: $\left\{\mathrm{O}, \mathrm{C}_{\alpha}, \mathrm{C}_{\beta}, \mathrm{C}\right.$, $\mathrm{H}_{\alpha}, \mathrm{H}$, and $\left.\mathrm{X}\right\} . \mathrm{C}_{\alpha}$ is always taken to be the carbon attached to the $\mathrm{O}, \mathrm{C}_{\beta}$ is taken to be the carbon attached to $\mathrm{C}_{\alpha}$ whenever the magnitude of its charge is greater than 0.3 (otherwise it is considered a $\mathrm{C}$ ), and all other carbon atoms are considered to be $\mathrm{C}$. Likewise, $\mathrm{H}_{\alpha}$ is the hydrogen attached to the $\mathrm{O}$ and all other hydrogen atoms are considered to be $\mathrm{H}$. There are 23 possible unique pair interactions between these 


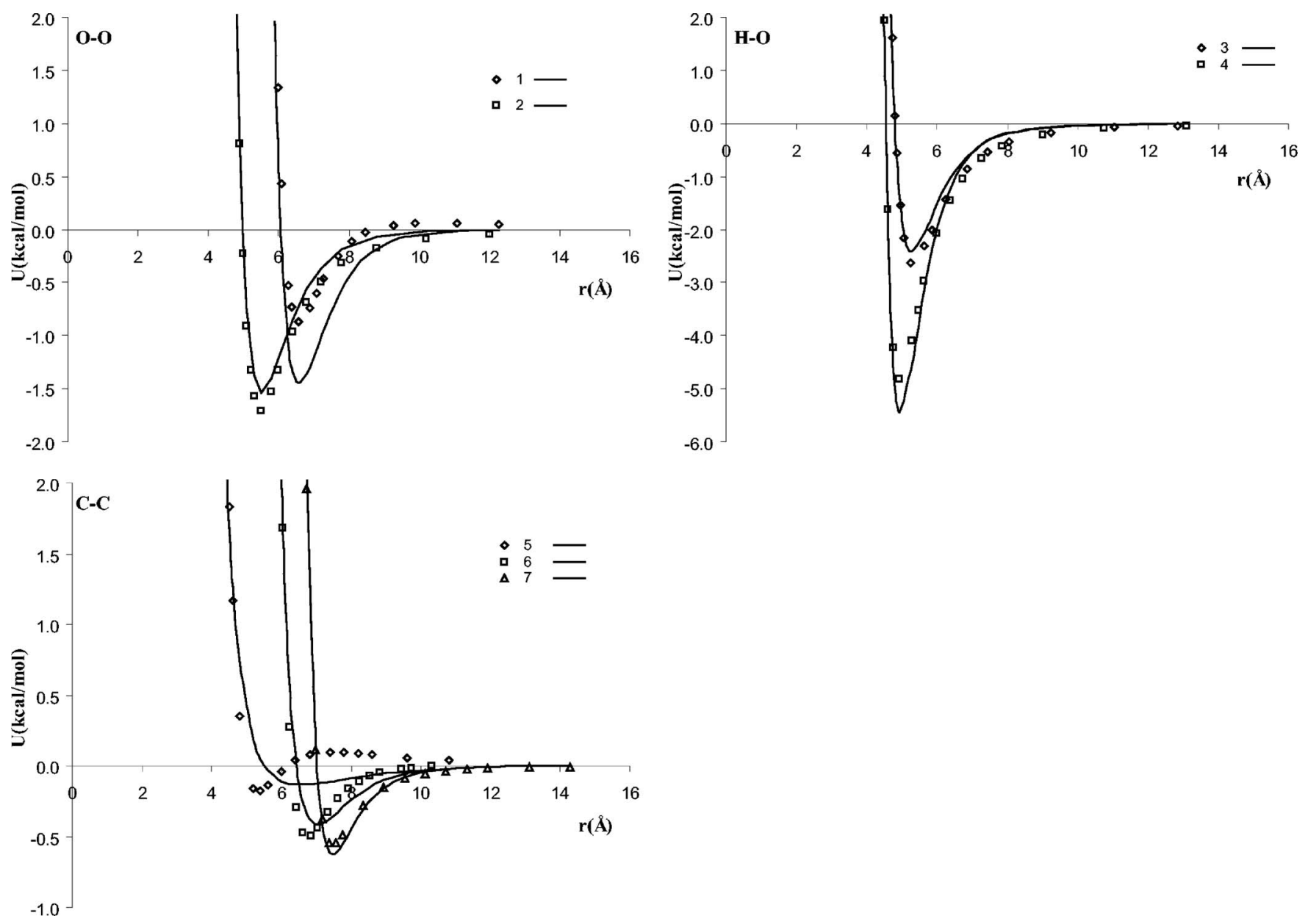

FIG. 7. Dimer energies for sec-butanol as a function of distance between $\mathrm{C}_{\alpha}$ monomer sites from ab initio calculations (points) and from the site-site model without point charges (lines).

sites, as defined here; these are shown in Table V. As mentioned, the NIPE constants are used for the $\mathrm{C}-\mathrm{C}, \mathrm{C}-\mathrm{H}$, and $\mathrm{H}-\mathrm{H}$ interactions, leaving 20 pair interactions to be parametrized.

Each alcohol energy landscape, except that for secbutanol, was regressed separately to obtain a best set of sitesite interaction parameters for that compound. Then a regression of all available alcohol energy surfaces, including those previously reported for methanol and ethanol, was performed to obtain a generalized set of alcohol site-site interaction parameters. The quality of the individual compound regressions serves as a best-case representation of the landscape using this model, and the quality of the simultaneous fit of all the alcohols relative to these best-case values is indicative of the transferability of the generalized parameters. A simulated annealing program was used to perform all of the regressions. Convergence to a global minimum was verified by varying the "cooling" rate and by using different initial parameter values.

Table $\mathrm{V}$ shows which energy landscapes were used in the regression of the generalized model parameters. All the generalized parameters except those for the $\mathrm{C}_{\beta}-\mathrm{C}$ interaction were obtained from a regression using the energy landscape data for methanol, ethanol, propanol, isopropanol, and

TABLE V. Pair interactions and the alcohol energy landscapes used to regress the generalized site-site interactions. NIPE parameters were used directly as constants; other interactions were obtained from energy landscapes for M (methanol), E (ethanol), P (propanol), I (isopropanol), T ( -butanol), and S (sec-butanol).

\begin{tabular}{|c|c|c|c|c|c|c|c|}
\hline Site-site & $\mathrm{O}$ & $C_{\alpha}$ & $C_{\beta}$ & $\mathrm{C}$ & $H_{\alpha}$ & $\mathrm{H}$ & $\mathrm{X}$ \\
\hline $\mathrm{O}$ & M,E,P,I,T & M,E,P,I,T & $\mathrm{I}, \mathrm{T}$ & E,P & M,E,P,I,T & M,E,P,I,T & $\cdots$ \\
\hline $\mathrm{C}_{\alpha}$ & $\cdots$ & M,E,P,I,T & $\mathrm{I}, \mathrm{T}$ & E,P & M,E,P,I,T & M,E,P,I,T & $\cdots$ \\
\hline $\mathrm{C}_{\beta}$ & $\cdots$ & $\ldots$ & $\mathrm{I}, \mathrm{T}$ & S & $\mathrm{I}, \mathrm{T}$ & $\mathrm{I}, \mathrm{T}$ & $\cdots$ \\
\hline $\mathrm{C}$ & $\cdots$ & $\cdots$ & $\ldots$ & NIPE & E,P & NIPE & $\cdots$ \\
\hline $\mathrm{H}_{\alpha}$ & $\cdots$ & $\cdots$ & $\cdots$ & $\cdots$ & M,E,P,I,T & M,E,P,I,T & M,E,P,I,T \\
\hline $\mathrm{H}$ & $\cdots$ & $\cdots$ & $\cdots$ & $\cdots$ & $\cdots$ & NIPE & $\cdots$ \\
\hline$X$ & $\ldots$ & $\ldots$ & $\ldots$ & $\ldots$ & $\ldots$ & $\ldots$ & M,E,P,I,T \\
\hline
\end{tabular}


$t$-butanol. As the $\mathrm{C}_{\beta}-\mathrm{C}$ interaction appears only in secbutanol, its parameters were obtained from a single regression of the sec-butanol energy landscape with all the other pair interaction parameters fixed at their previously determined generalized values.

The two models mentioned earlier, Eq. (2) with and without point charges, were regressed separately using the scheme described above to obtain the model parameters. For the model that included point charges, the small charges on $\mathrm{C}$ and $\mathrm{H}$ sites treated with the NIPE parameters were set to zero, and the remaining charges in the monomer were normalized to the values listed near the bottom of Table VI. The results of the regression are shown in the bottom line of Table VI as a sum of squared errors (SSE) per point, and the resultant pair potential model parameters are given in the main rows of Table VI. The SSE values suggest a reasonably good fit of the isopropanol and $t$-butanol energy landscapes but a poor fit of the propanol energy surface. This model does not produce transferable site-site interactions as is evident by the very large SSE for the simultaneous regression of all the alcohol energy surfaces to obtain generalized model parameters. No set of model parameters for the model with point charges is capable of representing the energy surfaces of these alcohols.

Similar results of the regression of the energy landscapes using the second model without point charges are shown in Table VII. The individual regressions all yielded smaller SSE values than the first model with point charges. The fit of the propanol energy surface without point charges was substantially improved over that obtained with the first model, the SSE now comparable to that of the other alcohols. A generalized set of parameters for the site-site model without point charges was also found that represents all the alcohol energy surfaces quite well. The SSE for this simultaneous regression shown in Table VI was a factor of 14 smaller than the model with charges. As reported in our earlier paper, the SSEs for the individual regressions of methanol and ethanol were 0.030 and $0.017 \mathrm{kcal}^{2} / \mathrm{mol}^{2}$, respectively. The SSE value of $0.054 \mathrm{kcal}^{2} / \mathrm{mol}^{2}$ obtained for the generalized six-alcohol regression shows a relatively small degradation in quality of fit relative to the individual regressions, and this indicates a reasonable level of transferability of the resultant parameters.

Figures 4-7 compare the fitted site-site model (without charges) to the ab initio data. In general, the site-site model reproduces quite accurately the very complex energy surface between all of the dimers. The very attractive wells associated with routes experiencing hydrogen bonding all show good agreement between the model and the ab initio data. So also, energies for routes dominated by smaller dispersion interactions, such as those labeled $\mathrm{C}-\mathrm{C}$, are also well represented by the model. There are, however, some differences between the model and the $a b$ initio data, particularly for the propanol routes which had the largest SSE of the four compounds. The propanol $\mathrm{O}-\mathrm{C}$ routes tended to be the most problematic. Though the model correctly reproduces the shapes of the attractive wells and the location of the well minima for routes P5, P6, and P7, it underestimates the well depth for P5 and P6 and overestimates the well depth for P7. The $\mathrm{O}-\mathrm{C}$ routes for the other dimer pairs do not have this
TABLE VI. Model parameters for Eq. (2) regressed with point charges. Parameter values are given in the order $\varepsilon(\mathrm{kcal} / \mathrm{mol}), A\left(\AA^{-1}\right)$, and $r^{*}(\AA)$, respectively, for Eq. (2) and in the order $B(\mathrm{kcal} / \mathrm{mol}), C\left(\AA^{-1}\right), r_{\text {ox }}(\AA)$ for the $\mathrm{X}-\mathrm{X}$ interaction.

\begin{tabular}{|c|c|c|c|c|}
\hline Interactions & Propanol & Isopropanol & $t$-Butanol & Generalized \\
\hline \multirow[t]{3}{*}{$\mathrm{O}-\mathrm{O}$} & 8.49553 & 0.00018 & 0.35077 & 0.30736 \\
\hline & 0.92558 & 1.30555 & 0.98537 & 1.54241 \\
\hline & 0.63383 & 4.15064 & 0.02004 & 3.31610 \\
\hline \multirow[t]{3}{*}{$\mathrm{O}-\mathrm{C}_{\alpha}$} & $3.22 \times 10^{-5}$ & 0.98892231 & 6.66671767 & 0.10265 \\
\hline & 0.77014 & 1.81595545 & 4.71130617 & 1.44251 \\
\hline & 2.60601 & 0.20438998 & 3.08187294 & 4.16285 \\
\hline \multirow[t]{3}{*}{$\mathrm{O}-\mathrm{C}_{\beta}$} & & 1.77969726 & 0.03711275 & 0.00246 \\
\hline & & 1.42189288 & 0.94851122 & 1.32872 \\
\hline & & 2.95854293 & 5.36465904 & 5.27058 \\
\hline \multirow[t]{3}{*}{$\mathrm{O}-\mathrm{C}$} & 7.16511 & & & 0.00274 \\
\hline & 1.46058 & & & 1.30328 \\
\hline & 2.56620 & & & 5.27074 \\
\hline \multirow[t]{3}{*}{$\mathrm{O}-\mathrm{H}_{\alpha}$} & 3.62499 & 15.9544 & 1.13535 & 19.51194 \\
\hline & 1.86370 & 3.12436 & 1.63019 & 2.08781 \\
\hline & 1.93570 & 0.06599 & 1.03279 & 0.01732 \\
\hline \multirow[t]{3}{*}{$\mathrm{O}-\mathrm{H}$} & $5.25 \times 10^{-5}$ & 0.00218 & 0.93160 & 0.14338 \\
\hline & 0.94677 & 1.88985 & 1.84494 & 1.74985 \\
\hline & 8.34965 & 4.01390 & 2.66174 & 2.90151 \\
\hline \multirow[t]{3}{*}{$\mathrm{C}_{\alpha}-\mathrm{C}_{\alpha}$} & 4.59598 & 2.29009 & 1.52159 & 1.43877 \\
\hline & 1.30023 & 1.23866 & 5.83586 & 2.05302 \\
\hline & 2.91905 & 3.42622 & 2.08182 & 3.14799 \\
\hline \multirow[t]{3}{*}{$\mathrm{C}_{\alpha}-\mathrm{C}_{\beta}$} & & 0.02479 & 3.53950 & 0.07073 \\
\hline & & 0.96341 & 5.04467 & 1.02425 \\
\hline & & 5.90775 & 0.34203 & 3.84776 \\
\hline \multirow[t]{3}{*}{$\mathrm{C}_{\alpha}-\mathrm{C}$} & 0.00988 & & & 0.28592322 \\
\hline & 0.32723 & & & 1.01237541 \\
\hline & 10.86297 & & & 3.90617626 \\
\hline \multirow[t]{3}{*}{$\mathrm{C}_{\alpha}-\mathrm{H}_{\alpha}$} & 1.74907 & 5.84040 & 7.17781 & 7.08901 \\
\hline & 2.82768 & 1.80052 & 12.5826 & 13.29573 \\
\hline & 2.39006 & 2.52907 & 0.45748 & 0.27240 \\
\hline \multirow[t]{3}{*}{$\mathrm{C}_{\alpha}-\mathrm{H}$} & 5.72079 & 2.22499 & 6.90572 & 6.50080 \\
\hline & 4.84776 & 3.25452 & 5.08635 & 5.29626 \\
\hline & 0.59719 & 2.48372 & 0.12069 & 0.45233 \\
\hline \multirow[t]{3}{*}{$\mathrm{C}_{\beta}-\mathrm{C}_{\beta}$} & & 0.01109 & $7.20 \times 10^{-5}$ & 0.20088 \\
\hline & & 1.30211 & 1.62263 & 1.21855 \\
\hline & & 5.07556 & 6.12135 & 3.98831 \\
\hline \multirow[t]{3}{*}{$\mathrm{C}_{\beta}-\mathrm{H}_{\alpha}$} & & 6.93207 & 0.00094 & 7.08487 \\
\hline & & 1.44781 & 2.23837 & 6.92291 \\
\hline & & 0.00016 & 3.68882 & 0.23119 \\
\hline \multirow[t]{3}{*}{$\mathrm{C}_{\beta}-\mathrm{H}$} & & 0.62421 & 0.40228 & 6.45714 \\
\hline & & 2.02225 & 2.12710 & 2.93847 \\
\hline & & 2.48069 & 2.82967 & 1.52104 \\
\hline \multirow[t]{3}{*}{$\mathrm{C}-\mathrm{H}_{\alpha}$} & 0.06420 & & & 7.08559 \\
\hline & 10.0154 & & & 6.92256 \\
\hline & 0.05743 & & & 0.13676 \\
\hline \multirow[t]{3}{*}{$\mathrm{H}_{\alpha}-\mathrm{H}_{\alpha}$} & $5.70 \times 10^{-11}$ & 0.08017 & $9.38 \times 10^{-7}$ & 0.00032 \\
\hline & 0.96548 & 1.18548 & 0.63126 & 1.64308 \\
\hline & 15.31258 & 4.53090 & 9.41265 & 4.62052 \\
\hline \multirow[t]{3}{*}{$\mathrm{H}_{\alpha}-\mathrm{H}$} & 0.68595 & 0.00288 & $1.04 \times 10^{-6}$ & $1.27 \times 10^{-7}$ \\
\hline & 4.62637 & 0.70015 & 0.68373 & 2.75686 \\
\hline & 0.00015 & 6.94192 & 11.92250 & 4.19078 \\
\hline \multirow[t]{3}{*}{$X-X$} & 1.01003 & 6.71252 & 10.88915 & 10.67909 \\
\hline & 4.24133 & 0.78321 & 0.89573 & 2.35749 \\
\hline & 0.44839 & 1.10559 & 1.01628 & 1.18084 \\
\hline $\mathrm{H}-\mathrm{X}$ & 0.00093 & 0.37493 & 1.38540 & 0.08650 \\
\hline & 0.67026 & 2.92862 & 1.63863 & 1.71150 \\
\hline & 7.77537 & 0.82349 & 1.39415 & 2.30229 \\
\hline
\end{tabular}


TABLE VI. (Continued.)

\begin{tabular}{|c|c|c|c|c|}
\hline Interactions & Propanol & Isopropanol & $t$-Butanol & Generalized \\
\hline \multirow{3}{*}{$\begin{array}{c}\mathrm{C}-\mathrm{C} \\
(\mathrm{NIPE})\end{array}$} & 0.05133 & & & 0.05133 \\
\hline & 1.45985 & & & 1.45985 \\
\hline & 4.34117 & & & 4.34117 \\
\hline \multirow{3}{*}{$\begin{array}{c}\mathrm{C}-\mathrm{H} \\
(\mathrm{NIPE})\end{array}$} & 0.35562 & & & 0.35562 \\
\hline & 2.11174 & & & 2.11174 \\
\hline & 2.60211 & & & 2.60211 \\
\hline \multirow{4}{*}{$\begin{array}{c}\mathrm{H}-\mathrm{H} \\
(\mathrm{NIPE})\end{array}$} & 0.01048 & 0.01048 & 0.01048 & 0.01048 \\
\hline & 1.26072 & 1.26072 & 1.26072 & 1.26072 \\
\hline & 3.97536 & 3.97536 & 3.97536 & 3.97536 \\
\hline & \multicolumn{4}{|c|}{ Normalized charges (no charge on NIPE sites) } \\
\hline $\mathrm{O}$ & -0.6264 & -0.6063 & -0.6101 & See \\
\hline $\mathrm{C}_{\alpha}$ & 0.2255 & 0.7296 & 0.9458 & individual \\
\hline $\mathrm{C}_{\beta 1}$ & 0 & -0.3119 & -0.3247 & alcohols \\
\hline $\mathrm{C}_{\beta 2}$ & 0 & 0 & -0.1971 & \\
\hline $\mathrm{H}_{\alpha}$ & 0.4009 & 0.5005 & 0.5109 & \\
\hline $\mathbf{S S E}^{\mathrm{a} / \text { point }}$ & $\begin{array}{c}0.115 \\
\mathrm{kcal}^{2} / \mathrm{mol}^{2}\end{array}$ & $\begin{array}{c}0.019 \\
\mathrm{kcal}^{2} / \mathrm{mol}^{2}\end{array}$ & $\begin{array}{c}0.033 \\
\mathrm{kcal}^{2} / \mathrm{mol}^{2}\end{array}$ & $\begin{array}{c}0.789 \\
\mathrm{kcal}^{2} / \mathrm{mol}^{2}\end{array}$ \\
\hline
\end{tabular}

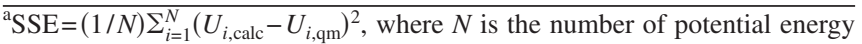
points in the regression, $U_{i, \text { calc }}$ is the site-site model potential energy [Eqs. (1) and (2)] and $U_{i, \mathrm{qm}}$ is the ab initio potential energy.

problem, likely because the $\mathrm{C}$ attached to the $\mathrm{C}_{\alpha}$ is treated as a $\mathrm{C}_{\beta}$ site in the isopropanol and $t$-butanol routes but as a NIPE C site for propanol. Using a $\mathrm{C}_{\beta}$ site in propanol does not give better overall results because as the ESP charges indicate, the $\mathrm{C}$ attached to $\mathrm{C}_{\alpha}$ in propanol is clearly different than the $\mathrm{C}_{\beta}$ sites. We chose not to define a separate $\mathrm{C}_{\beta}$ site for propanol, but rather to treat all $\mathrm{C}$ atoms with ESP charges of magnitude smaller than 0.3 as NIPE C sites. The P16 route is interesting with its gradual repulsive nature. The model reproduces this behavior reasonably accurately but has a small anomalous shoulder in the repulsion just beyond $4 \AA$. This is likely because of the competing $\mathrm{O}-\mathrm{O}, \mathrm{O}-\mathrm{H}_{\alpha}$, and $\mathrm{C}-\mathrm{H}_{\alpha}$ site-site interactions along this route. The regressed site-site model replicates quite well the short-range attraction exhibited in P9, and while it does qualitatively show the interesting intermediate repulsive potential observed in the $a b$ initio results, it does not quite capture all the subtleties of the competitive repulsions and attractions that produce the repulsive magnitude shown in the quantum mechanical results.

The sec-butanol landscapes were largely generated as a test set for the regressed model. As mentioned above, the only parameters regressed from this data were the $\mathrm{C}_{\beta}-\mathrm{C}$ parameters; all others were fixed at the values obtained from the generalized regression that did not include sec-butanol data. Again the deep routes dominated by hydrogen bonding (S3 and S4) are reproduced very accurately. The model potential energies for routes S1, S3, S4, S6, and S7 in Fig. 7 accurately reproduce the $a b$ initio data. The model predicts the correct attractive energy for route S5 and correctly models the repulsive portion of the potential energy curve, but it misses slightly the location of the minimum and it does not show the very small repulsion region at intermediate distances exhibited by the $a b$ initio data. The worst prediction by the model is for route $\mathrm{S} 1$, in which the depth and breadth of the attractive well are overpredicted. Nevertheless, the
TABLE VII. Model parameters for Eq. (2) regressed without point charges. Parameter values are given in the order $\varepsilon(\mathrm{kcal} / \mathrm{mol}), A\left(\AA^{-1}\right)$, and $r^{*}(\AA)$, respectively, for Eq. (4) and in the order $B(\mathrm{kcal} / \mathrm{mol}), C\left(\AA^{-1}\right), r_{\mathrm{ox}}(\AA)$ for the $\mathrm{X}-\mathrm{X}$ interaction.

\begin{tabular}{|c|c|c|c|c|}
\hline Interactions & Propanol & Isopropanol & $t$-Butanol & Generalized \\
\hline \multirow[t]{3}{*}{$\mathrm{O}-\mathrm{O}$} & 0.02699 & 2.91946 & 0.28200 & 0.09554 \\
\hline & 1.55297 & 0.91753 & 0.67001 & 1.30686 \\
\hline & 4.36324 & 2.69460 & 3.43503 & 4.23958 \\
\hline \multirow[t]{3}{*}{$\mathrm{O}-\mathrm{C}_{\alpha}$} & 3.25641 & 5.42241 & 10.87002 & 0.12351 \\
\hline & 1.75239 & 2.03729 & 3.42971 & 1.43415 \\
\hline & 2.71961 & 2.97975 & 2.92472 & 3.84828 \\
\hline \multirow[t]{3}{*}{$\mathrm{O}-\mathrm{C}_{\beta}$} & & 0.05166 & 0.19798 & 0.00105 \\
\hline & & 1.06183 & 1.01380 & 2.00742 \\
\hline & & 4.64733 & 4.21499 & 4.71099 \\
\hline \multirow[t]{3}{*}{$\mathrm{O}-\mathrm{C}$} & 3.81884 & & & 0.00023 \\
\hline & 1.63711 & & & 1.84353 \\
\hline & 2.81496 & & & 5.30422 \\
\hline \multirow[t]{3}{*}{$\mathrm{O}-\mathrm{H}_{\alpha}$} & 14.1998 & 19.76650 & 19.76140 & 13.37090 \\
\hline & 1.59353 & 1.29381 & 1.54888 & 1.51462 \\
\hline & 1.33722 & 0.46539 & 0.87739 & 1.47007 \\
\hline \multirow[t]{3}{*}{$\mathrm{O}-\mathrm{H}$} & 0.00255 & 0.09786 & 0.18011 & 0.34752 \\
\hline & 0.92900 & 1.62739 & 2.20034 & 1.45696 \\
\hline & 6.28488 & 3.25874 & 2.89869 & 2.81995 \\
\hline \multirow{3}{*}{$\mathrm{C}_{\alpha}-\mathrm{C}_{\alpha}$} & $9.43 \times 10^{-11}$ & 0.39728 & 0.39732 & 0.27608 \\
\hline & 8.35216 & 5.82468 & 5.82493 & 3.33004 \\
\hline & 3.49336 & 2.07739 & 2.07825 & 3.11863 \\
\hline \multirow[t]{3}{*}{$\mathrm{C}_{\alpha}-\mathrm{C}_{\beta}$} & & 3.54717 & 3.54727 & $8.19 \times 10^{-11}$ \\
\hline & & 5.03852 & 5.03739 & 2.35939 \\
\hline & & 0.77102 & 0.77321 & 3.59749 \\
\hline \multirow[t]{3}{*}{$\mathrm{C}_{\alpha}-\mathrm{C}$} & 0.38734 & & & 0.09808 \\
\hline & 2.39394 & & & 1.66935 \\
\hline & 3.71297 & & & 3.95290 \\
\hline \multirow[t]{3}{*}{$\mathrm{C}_{\alpha}-\mathrm{H}_{\alpha}$} & 6.16366 & 6.55655 & 6.55655 & 6.59601 \\
\hline & 12.80602 & 12.27197 & 12.27201 & 12.50721 \\
\hline & 0.53986 & 0.45919 & 0.45919 & 0.42152 \\
\hline \multirow[t]{3}{*}{$\mathrm{C}_{\alpha}-\mathrm{H}$} & 6.85801471 & 6.91238 & 6.91240 & 4.87325 \\
\hline & 9.44965887 & 5.10036 & 5.10347 & 13.64387 \\
\hline & 0.59962239 & 0.48124 & 0.47158 & $1.39 \times 10^{-6}$ \\
\hline \multirow[t]{3}{*}{$\mathrm{C}_{\beta}-\mathrm{C}_{\beta}$} & & 0.00858 & 0.00411 & 0.10493 \\
\hline & & 0.61920 & 0.90163 & 1.06490 \\
\hline & & 8.69904 & 6.73489 & 4.71193 \\
\hline \multirow[t]{3}{*}{$\mathrm{C}_{\beta}-\mathrm{C}$} & & & & 0.04660 \\
\hline & & & & 1.65098 \\
\hline & & & & 4.28672 \\
\hline \multirow[t]{3}{*}{$\mathrm{C}_{\beta}-\mathrm{H}_{\alpha}$} & & 5.84902 & 3.04955 & 1.08567 \\
\hline & & 2.44652 & 3.02066 & 3.12646 \\
\hline & & 1.94171 & 2.06488 & 2.15110 \\
\hline \multirow[t]{3}{*}{$\mathrm{C}_{\beta}-\mathrm{H}$} & & 2.19752 & 0.65620 & 0.70262 \\
\hline & & 1.59163 & 2.02685 & 2.56557 \\
\hline & & 2.36434 & 2.68576 & 2.46789 \\
\hline \multirow[t]{3}{*}{$\mathrm{C}-\mathrm{H}_{\alpha}$} & 0.01640 & & & 1.81104 \\
\hline & 5.48517 & & & 1.66223 \\
\hline & 0.09833 & & & 1.66875 \\
\hline \multirow[t]{3}{*}{$\mathrm{H}_{\alpha}-\mathrm{H}_{\alpha}$} & $5.20 \times 10^{-5}$ & 0.00012 & $5.83 \times 10^{-6}$ & 0.00203 \\
\hline & 0.71741 & 0.71421 & 0.19042 & 0.62605 \\
\hline & 10.27010 & 10.31846 & 9.19959 & 8.65018 \\
\hline \multirow[t]{3}{*}{$\mathrm{H}_{\alpha}-\mathrm{H}$} & $8.95 \times 10^{-7}$ & $1.58 \times 10^{-5}$ & $8.20 \times 10^{-6}$ & $8.36 \times 10^{-7}$ \\
\hline & 2.64415 & 1.33238 & 1.21926 & 0.77771 \\
\hline & 4.35993 & 6.37514 & 6.93935 & 10.94559 \\
\hline $\mathrm{X}-\mathrm{X}$ & 4.89752 & 8.14475 & 19.9993 & 14.19310 \\
\hline & 0.66389 & 0.82230 & 0.88822 & 0.76457 \\
\hline & 1.32130 & 1.49919 & 0.84907 & 0.90143 \\
\hline
\end{tabular}


TABLE VII. (Continued.)

\begin{tabular}{|c|c|c|c|c|}
\hline Interactions & Propanol & Isopropanol & $t$-Butanol & Generalized \\
\hline \multirow[t]{3}{*}{$\mathrm{H}-\mathrm{X}$} & 0.46928 & 0.19788 & 0.41755 & 0.71188 \\
\hline & 0.75041 & 0.90163 & 1.40685 & 0.60378 \\
\hline & 1.94579 & 1.049170 & 2.14869 & 1.52510 \\
\hline \multirow{3}{*}{$\begin{array}{c}\mathrm{C}-\mathrm{C} \\
(\mathrm{NIPE})\end{array}$} & 0.05133 & & & 0.05133 \\
\hline & 1.45985 & & & 1.45985 \\
\hline & 4.34117 & & & 4.34117 \\
\hline \multirow{3}{*}{$\begin{array}{c}\mathrm{C}-\mathrm{H} \\
(\mathrm{NIPE})\end{array}$} & 0.35562 & & & 0.35562 \\
\hline & 2.11174 & & & 2.11174 \\
\hline & 2.60211 & & & 2.60211 \\
\hline \multirow{3}{*}{$\begin{array}{c}\mathrm{H}-\mathrm{H} \\
(\mathrm{NIPE})\end{array}$} & 0.01048 & 0.01048 & 0.01048 & 0.01048 \\
\hline & 1.26072 & 1.26072 & 1.26072 & 1.26072 \\
\hline & 3.97536 & 3.97536 & 3.97536 & 3.97536 \\
\hline SSE/point & $\begin{array}{c}0.019 \\
\mathrm{kcal}^{2} / \mathrm{mol}^{2}\end{array}$ & $\begin{array}{c}0.010 \\
\mathrm{kcal}^{2} / \mathrm{mol}^{2}\end{array}$ & $\begin{array}{c}0.018 \\
\mathrm{kcal}^{2} / \mathrm{mol}^{2}\end{array}$ & $\begin{array}{c}0.054 \\
\mathrm{kcal}^{2} / \mathrm{mol}^{2}\end{array}$ \\
\hline
\end{tabular}

site-site model without charges does a rather remarkable job of modeling the different and very complex $a b$ initio energy landscapes of all of the dimers studied. Moreover, the quality of fit for the overall regression suggests that the transferability of the generalized parameters obtained is quite good.

\section{SUMMARY}

We have calculated $735 \mathrm{CP}$-corrected energies for homogenous dimers of propanol, isopropanol, $t$-butanol, and sec-butanol using MP2/6-311+G(2df,2pd). These points constitute 49 different approach routes that focus on specific types of intermolecular interactions, but as a whole provide comprehensive potential energy surfaces for the dimers. Routes providing opportunity for hydrogen bonding show deep attractive wells, but the dispersion interactions emphasized in other relative monomer orientations are also significant. Much of the qualitative complexity of each potential energy surface can be understood in terms of the charge distribution calculated within the rigid monomers. Interesting topography of the landscapes can be understood in terms of competing attractions and repulsions between different sites within the dimer.

The complexities of these energy landscapes provide a good challenge and validation opportunity for site-site models, employing spherical symmetry about atomic centers. We have successfully modeled the $a b$ initio potential energy surfaces using a pairwise-additive, site-site model based on a modified Morse potential. A generalized set of parameters reproduces quite well the potential energy landscapes of all the small alcohols containing up to four carbon atoms. This suggests a fairly good level of transferability for the site-site interactions to other alcohol molecules, though we have not yet tested the use of these model parameters in larger alcohols. A similar model that includes point charges to represent the permanent charge distribution was not as effective in modeling these surfaces and the resultant parameters were not transferable to other molecules. The transferable site-site model without charges provides a very good representation of the $a b$ initio hydrogen bond potential wells. It also represents the energy scans of most of the routes, in which dispersion dominates the attraction between the pairs including some of the unusual and complex features of some of the routes. The most significant differences between the ab initio and model data are for the O-C-type routes for the propanol dimer. Treating the $\mathrm{C}$ atom attached to the $\mathrm{C}_{\alpha}$ atom in propanol as a different site could perhaps improve these results, but we have not undertaken to improve the fit in this manner in order to maintain a clearly defined set of site interaction parameters that can be applied, at least in principle, to other alcohols.

${ }^{1}$ R. L. Rowley, C. M. Tracy, and T. A. Pakkanen, J. Chem. Phys. 125, 154302 (2006).

${ }^{2}$ R. L. Rowley and T. Pakkanen, J. Chem. Phys. 110, 3368 (1999).

${ }^{3}$ J.-P. Jalkanen, T. A. Pakkanen, and R. L. Rowley, J. Chem. Phys. 120, 1705 (2004)

${ }^{4}$ J.-P. Jalkanen, T. A. Pakkanen, Y. Yang, and R. L. Rowley, J. Chem. Phys. 118, 5474 (2003).

${ }^{5}$ R. L. Rowley, Y. Yang, and T. A. Pakkanen, J. Chem. Phys. 114, 6058 (2001).

${ }^{6}$ J.-P. Jalkanen, R. Mahlanen, T. A. Pakkanen, and R. L. Rowley, J. Chem. Phys. 116, 1303 (2002).

${ }^{7}$ R. Mahlanen, J.-P. Jalkanen, and T. A. Pakkanen, Chem. Phys. 313, 271 (2005).

${ }^{8}$ S. L. Garrison and S. I. Sandler, J. Phys. Chem. B 108, 18972 (2004).

${ }^{9}$ J. M. Hayes, J. C. Greer, and D. A. Morton-Blake, J. Comput. Chem. 25, 1953 (2004).

${ }^{10}$ W. L. Jorgensen, J. Am. Chem. Soc. 103, 335 (1981).

${ }^{11}$ B. Chen, J. J. Potoff, and J. I. Siepmann, J. Phys. Chem. B 105, 3093 (2001).

${ }^{12} \mathrm{H}$. Zhang and J. F. Ely, Fluid Phase Equilib. 217, 111 (2004).

${ }^{13}$ Y. Boutard, Ph. Ungerer, J. M. Teuler, M. G. Ahunbay, S. F. Sabater, J. Perez-Pellitero, A. D. Mackie, and E. Bourasseau, Fluid Phase Equilib. 236, 25 (2005).

${ }^{14}$ A. K. Sum, S. I. Sandler, R. Bukowski, and K. Szalewicz, J. Chem. Phys. 116, 7627 (2002).

${ }^{15}$ M. J. Frisch, G. W. Trucks, H. B. Schlegel et al., GAUSSIAN 98, Revision A.6, Gaussian, Inc., Pittsburgh, PA, 1998.

${ }^{16}$ S. Tsuzuki and H. P. Luthi, J. Chem. Phys. 114, 3949 (2001).

${ }^{17}$ S. Tsuzuki, T. Uchimaru, and K. Tanabe, Chem. Phys. Lett. 287, 202 (1998).

${ }^{18}$ S. Tsuzuki, T. Uchimaru, M. Mikami, and S. Urata, J. Chem. Phys. 121, 9917 (2004); J. Phys. Chem. A 107, 7962 (2003).

${ }^{19}$ A. J. Stone, The Theory of Intermolecular Forces (Clarendon, Oxford, 1996).

${ }^{20}$ R. Ahlrichs, P. Penco, and G. Scoles, Chem. Phys. 19, 119 (1977). 